\title{
Determinants of Health Facility Delivery in Northwest Ethiopia: A Community-Based Case-Control Study
}

This article was published in the following Dove Press journal: International Journal of General Medicine

\begin{abstract}
Tadesse Guadu Delele iD Gashaw Andargie Biks ${ }^{2}$ Solomon Mekonnen Abebe ${ }^{3}$ Zemene Tigabu Kebede (iD ${ }^{4}$

'Department of Environmental and Occupational Health and Safety, Institute of Public Health, College of Medicine and Health Sciences, University of Gondar, Gondar, Ethiopia; ${ }^{2}$ Departments of Health System and Policy, Institute of Public Health, College of Medicine and Health Sciences, University of Gondar, Gondar, Ethiopia; ${ }^{3}$ Departments of Human Nutrition, Institute of Public Health, College of Medicine and Health Sciences, University of Gondar, Gondar, Ethiopia; ${ }^{4}$ Departments of Pediatrics and Child Health, School of Medicine, College of Medicine and Health Sciences, University of Gondar, Gondar, Ethiopia
\end{abstract}

Correspondence: Tadesse Guadu Delele P.O. Box Address 196, Gondar, Ethiopia Email tadeguade2@gmail.com
Background: Although Ethiopia has developed many strategies to promote health facility delivery, more than half of the women gave birth at home contributing to high maternal and neonatal mortality. Therefore, this study aimed to identify the determinants of health facility delivery in Northwest Ethiopia.

Methods: A community-based unmatched case-control study was conducted in selected districts in Northwest Ethiopia. The sample included 885 infant mothers (295 cases and 590 controls) from April 6-16, 2019. Data were collected using a pretested intervieweradministered structured questionnaire. A multivariable logistic regression model was used to identify predictors, and STATA 14 statistical software was used to analyze the data.

Results: The mean maternal age was 26.4 years $(\mathrm{SD} \pm 6.7)$ for cases and 28.1 years $(\mathrm{SD} \pm 6.8)$ for controls. The overall good newborn care qualities were $95.8 \%$ (206) for cases and $40.8 \%$ (262) for controls. Attending a formal education (AOR=2.1 (95\% CI: 1.5, 2.9)), having first pregnancy from 18 to 25 ( $\mathrm{AOR}=1.5(95 \% \mathrm{CI}: 1.1,2.1)$ ), living within $1 \mathrm{~km}$ distance from the nearest health center $(\mathrm{AOR}=2.5(95 \% \mathrm{CI}: 1.5,4.0))$, having $\mathrm{ANC}$ visits $(\mathrm{AOR}=3.9(95 \% \mathrm{CI}$ : $2.4,6.5))$, having a mobile $(\mathrm{AOR}=1.7(95 \% \mathrm{CI}: 1.3,2.4))$ were the determinants of health facility delivery.

Conclusion: Maternal education, not having pregnancy at early age, accessing health facilities to the nearby residents, attending antenatal care, and having a mobile were the determinants of health facility delivery. Therefore, strengthening education and healthseeking behavior of the mothers using a locally contextualized strategy is essential. Reaching mothers who are still far from health facility also deserves needs due attention.

Keywords: essential newborn care, delivery place, Northwest Ethiopia

\section{Plain Language Summary}

Although Ethiopia has developed many strategies to promote health facility delivery, most women gave birth at home leading to high maternal and neonatal mortality. This study aimed to identify the determinants of health facility delivery in Northwest Ethiopia. A communitybased unmatched case-control study was conducted in selected districts among 885 infant mothers (295 cases and 590 controls) in April, 2019. Data were collected using a pretested interviewer-administered structured questionnaire. A multivariable logistic regression model was used to identify predictors. The mean maternal age was 26.4 years ( $\mathrm{SD} \pm 6.7$ ) for cases and 28.1 years $(\mathrm{SD} \pm 6.8)$ for controls. The overall good newborn care qualities were $95.8 \%$ (206) for cases and 40.8\% (262) for controls. Attending a formal education, having first pregnancy from 18 to 25 , living within $1 \mathrm{~km}$ distance, having ANC visits, having a mobile were the determinants. Strengthening education and health-seeking behavior of the mothers 
using a locally contextualized strategy is essential. Reaching mothers who are still far from health facility needs due attention.

\section{Background}

Regardless of the great achievements in reducing maternal and neonatal deaths in the last two decades, Ethiopia keeps to have high maternal mortality with 412 maternal deaths per 100,000 live births and neonatal mortality with 29 neonatal deaths per 1000 live births. ${ }^{1}$ Currently, neonatal mortality rate in Ethiopia is higher (30) than the African estimation (26.7) and the overall global estimation (18) per 1000 live births. ${ }^{2,3}$ Ethiopia Mini-Demographic Health Survey 2019 indicated that there is a slight increase in neonatal mortality compared to the 2016 survey finding, and a large proportion of maternal and neonatal deaths occur during the 48 hours after delivery. ${ }^{1}$ Promoting health facility delivery is one strategy for improving maternal and newborn health outcomes. ${ }^{4}$ The World Health Organization (WHO) recommended health facility delivery to appropriately utilize the maternal and newborn care services to reduce the major causes of maternal and neonatal deaths. ${ }^{5}$ It is a strategic approach rendered during the time of pregnancy, during, delivery, and soon after birth and during the postnatal period. ${ }^{3}$ For all newborns, clean delivery and cord care, thermal protection, early and exclusive breastfeeding, and immunization are recommended by the WHO. ${ }^{6,7}$

To improve health facility delivery, the Ethiopian government did various health interventions by implementing a health extension program, training midwives, enhancing the referral system, integrating health services, and routine immunization. The second Health Sector Transformation Plan (HSTP) of Ethiopia highlighted as newborn health was amongst the key priorities of the government and the ultimate goal of this reproductive health program was to reduce the neonatal mortality rate to 10 per 1000 live births by $2020 .^{8}$ Nonetheless, health facility delivery is still remained low (48\%) and neonatal death is high (30/ 1000 live births), and its 41/1000 live births in the study area (Northwest Ethiopia). ${ }^{2,9}$

Health facility delivery service utilization has been encouraged to improve maternal health and newborn survival. ${ }^{10}$ However, most mothers in Ethiopia deliver at home in the presence of traditional birth attendants, which has resulted in many harmful traditional practices applied to the newborn. ${ }^{11,12}$ Even though some women gave birth by skilled birth attendants in a health facility, newborn care practice may be affected by traditional practices after discharge at home by the family and community. In low and middle-income countries, there are different cultural newborn care practices at home which are in contrast to WHO recommendations. Culturally sensitive maternal and newborn care practice is important to assure the well-being of mothers and newborns. ${ }^{7,13}$

Different studies identified various factors associated with health facility delivery service utilization including maternal education, attending antenatal care, counseling about essential newborn care (ENBC), postnatal care (PNC) visits, place of residence, household wealth index, and partner's educational level. ${ }^{14-16}$ Health facility delivery service utilization could also be affected by a multitude of factors including availability and readiness of health care services, distance, cost, and quality of service, personal health beliefs and socioeconomic factors. $^{17-20}$

The readiness of health institutions for facility delivery is vital for increasing the utilization of maternal and newborn care services, ${ }^{21}$ and ultimately reducing maternal and neonatal deaths. ${ }^{3}$ The presence of good essential newborn care services indicates health system readiness to manage delivery and childbirth complications. ${ }^{22}$ Studies have shown that proper essential newborn care services would reduce up to $60 \%$ of maternal deaths and $85 \%$ of intrapartum related neonatal deaths annually. ${ }^{23}$ However, the reason for low utilization of health facility delivery was not well addressed, few of these studies which were crosssectional by its design have methodological limitations, and did not address the causal relationship between the outcome and explanatory variables. Therefore, this study aimed to identify the determinants of health facility delivery in Northwest Ethiopia.

\section{Methods}

\section{Study Area and Design}

A community-based unmatched case-control study was conducted from April 6-16, 2019. This study was conducted in Gondar, which is found in the Northwestern part of Ethiopia encompasses the North and Central Gondar administrative zones. Dabat and Debark districts from the North Gondar, and Wogera district from the Central Gondar administrative zones were included. The total population of this area was projected to be 3.7 million in 2017. Of this population, 1.8 million (49\%) were females. The study area has three government hospitals and 50 health centers. ${ }^{1}$ 


\section{Source and Study Population}

The source population for the study was all women aged 15-49 years who gave birth in the last six months in North and Central Gondar zones, while the study population was women who were residing in the selected districts (Dabat, Debark, and Wogera). Cases were women who gave birth to their last child in health institutions in the six months. Controls were women who give birth to their last child at home in the six months in the selected districts.

\section{Sample Size Determination and Sampling Strategy}

The sample size was determined using a proportional difference approach for case-control study using Epi Info version 7 considering the following assumptions: 95\% confidence level, $80 \%$ power, case to control ratio of $1: 2$, the proportion of illiterate mothers or caretakers among cases was $42.6 \%{ }^{24}$ Assuming a $10 \%$ difference (increase) in illiteracy level among controls in advance, the proportion of controls with exposure becomes $52.6 \%$ producing an odds ratio of 2.01 to be detected. Accordingly, after adding a $10 \%$ non-response rate to each and a design effect of 2, the total sample size was 885 (295 cases and 590 controls).

A multistage-stratified random sampling technique was employed to identify each respondent. Initially, Northwest Ethiopia was stratified as North Gondar and Central Gondar zones. Then, 2 districts (Dabat and Debark) were randomly selected from the 6 districts in the North Gondar zone and, Wogera district was conveniently selected from Central Gondar zone. At the second stage, 10, 6, and 8 kebeles (the smallest administrative unit) were randomly selected from Dabat, Debark, and Wogera districts, respectively. The number of kebeles was selected proportional to its size in each district. The study participants were mothers who deliver in health facility (cases) and at home (controls) in the last six months. The list of deliveries were obtained from health extension workers record sheets in each kebele. Finally, the cases and controls fulfilling the inclusion criteria were selected by employing a systematic random sampling technique.

\section{Data Collection Methods and Tools}

Data were collected by using pretested intervieweradministered structured questionnaires, which were adapted from the WHO minimum neonatal care package. ${ }^{3}$ The questionnaire was prepared in English, then translated into the local language "Amharic" and used to collect data using a tablet-based data collection application software called Open Data Kit (ODK) software. Face to face interview was conducted by six trained data collectors who are first-degree female midwives and nurses. A one-day training was given to data collectors and supervisors on how to extract information from respondents, ethical aspects, and ways of communication before data collection commencement.

\section{Variables}

Dependent Variable

Place of delivery.

\section{Independent Variables}

Sociodemographic characteristics (age, residence, marital status, occupation, education, household income, religion, and media use), reproductive and obstetric characteristics of the mother's (age at first marriage and pregnancy, number of children, and gravidity, parity, the experience of neonatal death, ANC visits, obstetric danger signs, plan for last pregnancy, gestational age, knowledge, and experience on neonatal danger signs).

\section{Data Processing and Analysis}

The data were entered and cleaned using the Epi-Info version 7.1.5.0 software. Cleaning was made by running frequencies, proportions, and summary statistics. The Principal Component Analysis (PCA) was employed to generate a wealth asset. The cleaned data were exported to STATA version 14 software for analysis. Bivariate analysis was done to identify candidate variables using $p \leq$ 0.25 . Multi-collinearity between the candidate variables was checked. Then, multivariable analysis using a backward stepwise selection method was carried out to control for possible confounding variables and to determine the presence of statistical significance between explanatory variables and the outcome variable. Finally, statistical significance was declared at a p-value of $<0.05$, and odds ratio with $95 \% \mathrm{CI}$ was used to measure the degree of association between independent variables and place of delivery. Model fitness was also checked using Hosmer and Lemeshow goodness of a fit test.

\section{Results}

\section{Sociodemographic Characteristics}

A total of 859 mothers (215 cases and 644 controls) were included in the analysis making the response rate of 
97.1\%. The mean maternal age was 26.4 years $(\mathrm{SD} \pm 6.7)$ for cases and 28.1 years $(\mathrm{SD} \pm 6.8)$ for controls. The largest proportion, $200(93 \%)$ of the mothers among the cases and 621 (96.4\%) among controls were married, and 159 (74\%) of mothers among cases and $540(83.8 \%)$ among controls live beyond a kilometer distance from the nearest health center. Moreover, 109 (50.7\%) of the mothers among the cases and 464 (72.1\%) among controls had no formal education, and $93(43.3 \%)$ of mothers among the cases and $394(61.2 \%)$ among controls did not have a mobile (Table 1).

\section{Reproductive and Obstetric}

\section{Characteristics}

The majority of the controls 506 (78.6\%) and 149 (69.3\%) cases group had a marriage before 18 years of age. More than a quarter $62(28.8 \%)$ of the cases and $256(3.8 \%)$ of the controls had their first pregnancy before 18 years of age. A higher proportion, $194(90.2 \%)$ of the cases and 456 (70.8\%) of the controls had ANC attendance, while 82 $(42.2 \%)$ of the cases and $141(30.9 \%)$ of the controls had four ANC visits. The majorities of deliveries, 211 (98.1\%) of the cases and $632(98.3 \%)$ of the controls had term gestational age, and 188 (87.4\%) of the cases and $542(84.2 \%)$ of the controls were from planned pregnancies (Table 2).

\section{Determinant of Health Facility Delivery}

From all the variables included in the multivariable logistic regression model using backward elimination stepwise likelihood ratio method; maternal education, age at first pregnancy, home distance from the nearest health center, having a mobile, parity, and ANC visits were found to be significant determinants of health facility delivery. Among the newborn care services utilized; the level of thermal care, cord care, breastfeeding, immunization, safety practice, team-work, delivery service quality, and overall newborn care quality during delivery were significantly associated with health facility delivery in the study area.

The study showed that mothers who attended a formal education were two times (AOR=2.1 (95\% CI: 1.5, 2.9)) more likely to deliver in health facility as compared to mothers who did not attend a formal education. Mothers whose age range from 18 to 25 years of age at first pregnancy were two times (AOR=1.5 (95\% CI: 1.1, 2.1)) higher odds of health facility delivery as compared to those mothers whose age was less than 18 years of age.
Table I Sociodemographic Characteristics Among Mothers of Cases and Controls in Northwest Ethiopia, 2019 ( $N=859)$

\begin{tabular}{|c|c|c|c|}
\hline Variables & $\begin{array}{l}\text { Cases, } \\
\text { n (\%) }\end{array}$ & $\begin{array}{l}\text { Controls, } \\
\text { n (\%) }\end{array}$ & $\begin{array}{l}\text { Total, } \\
\text { n (\%) }\end{array}$ \\
\hline \multicolumn{4}{|l|}{ Maternal age (years) } \\
\hline$\leq 19$ & $31(14.4)$ & $49(7.6)$ & $80(9.3)$ \\
\hline $20-29$ & $114(53.0)$ & $318(49.4)$ & $432(50.3)$ \\
\hline $30-39$ & $60(27.9)$ & $232(36.0)$ & $292(34.0)$ \\
\hline$\geq 40$ & $10(4.7)$ & $45(7.0)$ & $55(6.4)$ \\
\hline \multicolumn{4}{|l|}{ Residence } \\
\hline Urban & $55(25.6)$ & $102(15.8)$ & $157(18.3)$ \\
\hline Rural & $160(74.4)$ & $542(84.2)$ & $702(81.7)$ \\
\hline \multicolumn{4}{|l|}{ Marital status } \\
\hline Married & $200(93.0)$ & $621(96.4)$ & $821(95.6)$ \\
\hline Not married* & $15(7.0)$ & $23(3.6)$ & $38(4.4)$ \\
\hline \multicolumn{4}{|l|}{ Mothers occupation } \\
\hline Housewife & $93(43.2)$ & $256(39.7)$ & $349(40.6)$ \\
\hline Farmer & $104(48.4)$ & $374(58.1)$ & $478(55.7)$ \\
\hline Others** & $18(8.4)$ & $14(2.2)$ & $32(3.7)$ \\
\hline \multicolumn{4}{|l|}{ Father occupation } \\
\hline Farmer & $186(86.5)$ & $611(94.9)$ & $797(92.8)$ \\
\hline Merchant & $17(7.9)$ & $22(3.4)$ & $39(4.5)$ \\
\hline Others $* * *$ & $12(5.6)$ & II (I.7) & $23(2.7)$ \\
\hline \multicolumn{4}{|l|}{$\begin{array}{l}\text { Education status of the } \\
\text { mother }\end{array}$} \\
\hline No formal education & $109(50.7)$ & $464(72.1)$ & $573(66.7)$ \\
\hline Formal education & $106(49.3)$ & $180(27.9)$ & $286(33.3)$ \\
\hline \multicolumn{4}{|l|}{$\begin{array}{l}\text { Education status of the } \\
\text { father }\end{array}$} \\
\hline No formal education & $102(47.4)$ & $393(61.0)$ & $495(57.6)$ \\
\hline Formal education & $113(52.6)$ & $251(39.0)$ & $364(42.4)$ \\
\hline \multicolumn{4}{|l|}{ Religion } \\
\hline Orthodox Christian & $212(98.6)$ & $627(97.4)$ & $839(97.7)$ \\
\hline Muslim & $03(1.4)$ & $17(2.6)$ & $20(2.3)$ \\
\hline \multicolumn{4}{|l|}{$\begin{array}{l}\text { Distance to the nearest } \\
\text { health center }\end{array}$} \\
\hline$\leq 1 \mathrm{~km}$ & $56(26.0)$ & $104(16.2)$ & $160(18.6)$ \\
\hline $\mathrm{I} . \mathrm{I}-5 \mathrm{~km}$ & 67 (3।.2) & $163(25.3)$ & $230(26.8)$ \\
\hline $5.1-10 \mathrm{~km}$ & $55(25.6)$ & $195(30.3)$ & $250(19.1)$ \\
\hline II.0-20 km & 37 (I7.2) & $182(28.2)$ & $219(25.5)$ \\
\hline \multicolumn{4}{|l|}{ Household income } \\
\hline Poor & $70(32.6)$ & $255(39.6)$ & $325(37.8)$ \\
\hline Medium & $69(32.1)$ & $211(32.8)$ & $280(32.6)$ \\
\hline Rich & $76(35.3)$ & $178(27.6)$ & $254(29.6)$ \\
\hline \multicolumn{4}{|l|}{ Have a mobile } \\
\hline Yes & $122(56.7)$ & $250(38.8)$ & $372(43.3)$ \\
\hline No & $93(43.3)$ & $394(61.2)$ & $487(56.7)$ \\
\hline
\end{tabular}

(Continued) 
Table I (Continued).

\begin{tabular}{|l|l|l|l|}
\hline Variables & $\begin{array}{l}\text { Cases, } \\
\text { n (\%) }\end{array}$ & $\begin{array}{l}\text { Controls, } \\
\text { n (\%) }\end{array}$ & $\begin{array}{l}\text { Total, } \\
\text { n (\%) }\end{array}$ \\
\hline $\begin{array}{l}\text { Have a radio or TV } \\
\text { Yes }\end{array}$ & $15(7.0)$ & $26(4.0)$ & $41(4.8)$ \\
No & $200(93.0)$ & $618(96.0)$ & $818(95.2)$ \\
\hline
\end{tabular}

Notes: *Single, divorced, separated and living together. **Daily laborer, private employ and student. ***Daily laborer and student.

Similarly, mothers living within $1 \mathrm{~km}$ distance from a health center were three times $(\mathrm{AOR}=2.5$ (95\% CI: 1.5 , 4.0)) higher odds of health facility delivery as compared to those mothers living beyond $11 \mathrm{~km}$.

Likewise, mothers who had ANC visits were four times (AOR=3.9 (95\% CI: 2.4, 6.5)) more likely to deliver in health facility as compared to those who did not have ANC visits. Mothers who have a mobile were two times $(\mathrm{AOR}=1.7(95 \% \mathrm{CI}: 1.3,2.4))$ more likely to deliver in health facility as compared to their counterparts. A unit increase in the birth order of mothers showed a $15 \%$ decrease in the odds of health facility delivery $(\mathrm{AOR}=0.85$ (95\% CI: 0.8, 0.9)) (Table 3).

\section{Discussion}

This study attempts to identify the determinant factors of health facility delivery in Northwest Ethiopia. This study showed that maternal education, age at first pregnancy, home distance from the nearest health center, having a mobile, parity, and ANC visits were the determinants of health facility delivery.

Mothers who had ANC visits were four times more likely to deliver in a health facility as compared to those who did not have ANC visits. This positive association is due to the fact that women who seek care for their pregnancy are more likely to seek care for their delivery. This finding is comparable with other previous studies done in Ethiopia and Tanzania. ${ }^{25-28}$ Antenatal care is the most promising entry point for mothers to get counseling about the risks and problems that they may encounter during delivery. Mothers who attended ANC already won the challenges of visiting health facility and hence, more likely to have a better understanding of ANC and possibly deliver in a health facility.

The odds of health facility delivery were two times higher among mothers having a formal education as
Table 2 Reproductive and Obstetric Characteristics Among Mothers of Cases and Controls in Northwest Ethiopia, 2019 $(\mathrm{N}=859)$

\begin{tabular}{|c|c|c|c|}
\hline Variables & $\begin{array}{l}\text { Cases, } \\
\text { n (\%) }\end{array}$ & $\begin{array}{l}\text { Controls, } \\
\text { n (\%) }\end{array}$ & $\begin{array}{l}\text { Total, } \\
\text { n (\%) }\end{array}$ \\
\hline \multicolumn{4}{|l|}{$\begin{array}{l}\text { Mather's age at first } \\
\text { marriage }\end{array}$} \\
\hline $7-14$ years & $63(29.3)$ & $211(32.8)$ & $274(31.9)$ \\
\hline $15-17$ years & $86(40.0)$ & $295(45.8)$ & $38 \mathrm{I}(44.4)$ \\
\hline$\geq 18$ years & $66(30.7)$ & $138(2 \mid .4)$ & $204(23.7)$ \\
\hline \multicolumn{4}{|l|}{$\begin{array}{l}\text { Mather's age at first } \\
\text { pregnancy }\end{array}$} \\
\hline $12-17$ years & $62(28.8)$ & $256(3.8)$ & $318(37.0)$ \\
\hline $18-25$ years & $145(67.4)$ & $378(58.7)$ & $523(60.9)$ \\
\hline $26-38$ years & $08(3.7)$ & $10(1.5)$ & $18(2.1)$ \\
\hline \multicolumn{4}{|l|}{$\begin{array}{l}\text { Number of pregnancies/ } \\
\text { gravidity/ }\end{array}$} \\
\hline I-3 Pregnancies & |4| (65.6) & $325(50.5)$ & $466(54.3)$ \\
\hline 4-6 Pregnancies & $58(27.0)$ & $263(40.8)$ & $321(37.4)$ \\
\hline 7-12 Pregnancies & $16(7.4)$ & $56(8.7)$ & $72(8.3)$ \\
\hline Birth order/parity/ & $215(25.0)$ & $644(75.0)$ & $859(100.0)$ \\
\hline \multicolumn{4}{|l|}{ ANC attendance } \\
\hline Yes & $194(90.2)$ & $456(70.8)$ & $650(75.7)$ \\
\hline No & $21(9.8)$ & $188(29.2)$ & $209(24.3)$ \\
\hline \multicolumn{4}{|l|}{$\begin{array}{l}\text { Number of ANC visits } \\
(n=650)\end{array}$} \\
\hline One & $14(7.2)$ & $53(11.6)$ & $67(10.3)$ \\
\hline Two & $29(15.0)$ & $83(18.2)$ & $112(17.2)$ \\
\hline Three & $69(35.6)$ & $179(39.3)$ & $248(38.2)$ \\
\hline Four & $82(42.2)$ & $|4|(30.9)$ & $223(34.3)$ \\
\hline \multicolumn{4}{|l|}{$\begin{array}{l}\text { Time of ANC follow-up } \\
(n=650)\end{array}$} \\
\hline$<12$ weeks & $52(26.8)$ & $75(16.5)$ & $127(19.5)$ \\
\hline 12-24 weeks & $119(61.3)$ & $316(69.3)$ & $435(67.0)$ \\
\hline$>24$ weeks & $23(11.9)$ & $65(14.2)$ & $88(13.5)$ \\
\hline \multicolumn{4}{|l|}{ Place of ANC visit $(n=650)$} \\
\hline Health post & $29(14.9)$ & III (24.3) & $140(2 \mid .5)$ \\
\hline Health center & I 46 (75.3) & $310(68.0)$ & $456(70.2)$ \\
\hline Hospital & $19(9.8)$ & $35(7.7)$ & $54(8.3)$ \\
\hline \multicolumn{4}{|l|}{ Obstetric danger sign } \\
\hline At least one danger sign & $31(14.4)$ & $98(15.2)$ & $129(15.0)$ \\
\hline No danger sign at all & $184(85.6)$ & $546(84.8)$ & $730(85.0)$ \\
\hline \multicolumn{4}{|l|}{ Last pregnancy planned } \\
\hline Yes & I88 (87.4) & $542(84.2)$ & $730(85.0)$ \\
\hline No & $27(12.6)$ & $102(15.8)$ & $129(15.0)$ \\
\hline \multicolumn{4}{|l|}{ Gestational age } \\
\hline Term & $211(98.1)$ & $632(98.1)$ & $843(98.3)$ \\
\hline Pre or post-term & $4(1.9)$ & $12(1.9)$ & $15(1.7)$ \\
\hline
\end{tabular}


Table 3 Determinant of Health Facility Delivery in Northwest Ethiopia, 2019

\begin{tabular}{|c|c|c|c|c|}
\hline Variables & Cases $\mathbf{N}(\%)$ & Controls N (\%) & COR $(95 \% \mathrm{Cl})$ & AOR $(95 \% \mathrm{Cl})$ \\
\hline \multicolumn{5}{|l|}{ Residence } \\
\hline Urban & $55(25.6)$ & $102(15.8)$ & $1.83(1.3,2.7)$ & \\
\hline Rural & $160(74.4)$ & $542(84.2)$ & 1 & \\
\hline \multicolumn{5}{|l|}{ Mothers occupation } \\
\hline Farmer & $104(48.4)$ & $374(58.1)$ & 1 & \\
\hline Housewife & $93(43.2)$ & $256(39.7)$ & $1.3(I .1, I .8)$ & \\
\hline Others+ & $18(8.4)$ & $14(2.2)$ & $4.6(2.2,9.6)$ & \\
\hline \multicolumn{5}{|l|}{ Mothers education status } \\
\hline No formal education & $109(50.7)$ & $464(72.1)$ & 1 & 1 \\
\hline Formal education & $106(49.3)$ & $180(27.9)$ & $2.5(1.8,3.4)$ & $2.1(1.5,2.9)^{* * * *}$ \\
\hline \multicolumn{5}{|l|}{ Education status of the father } \\
\hline No formal education & $102(47.4)$ & $393(61.0)$ & I & \\
\hline Formal education & $113(52.6)$ & $251(39.0)$ & $1.7(1.3,2.4)$ & \\
\hline \multicolumn{5}{|l|}{ Distance from the health center } \\
\hline$\leq \mathrm{l} \mathrm{km}$ & $56(26.0)$ & $104(16.2)$ & $2.6(1.6,4.2)$ & $2.5(1.5,4.0)^{* * *}$ \\
\hline I.I-5 km & $67(31.2)$ & $163(25.3)$ & $2.1(1.3,3.2)$ & $1.9(1.2,3.0)^{* *}$ \\
\hline $5.1-10 \mathrm{~km}$ & $55(25.6)$ & $195(30.3)$ & $\mathrm{I} .4(\mathrm{I} . \mathrm{I}, 2.2)$ & I.3 $(0.8,2.0)$ \\
\hline $11.0-20 \mathrm{~km}$ & $37(17.2)$ & $182(28.2)$ & I & 1 \\
\hline \multicolumn{5}{|l|}{ Have a mobile } \\
\hline Yes & $122(56.7)$ & $250(38.8)$ & $2.1(1.5,2.8)$ & $1.7(1.3,2.4)^{* *}$ \\
\hline No & $93(43.3)$ & $394(6 \mid .2)$ & 1 & \\
\hline \multicolumn{5}{|l|}{ Mather's age at first pregnancy } \\
\hline $12-17$ years & $62(28.8)$ & $256(3.8)$ & 1 & 1 \\
\hline I8-25 years & $145(67.4)$ & $378(58.7)$ & I.6 (I.I, 2.2) & $\mathrm{I} .5(\mathrm{I} . \mathrm{I}, 2 . \mathrm{I})^{*}$ \\
\hline $26-38$ years & $8(3.7)$ & $10(1.5)$ & $3.3(1.3,8.7)$ & $2.1(0.8,5.6)$ \\
\hline Birth order/parity/ & $215(25.0)$ & $644(75.0)$ & $0.8(0.7,0.9)$ & $0.85(0.8,0.9)^{* * *}$ \\
\hline \multicolumn{5}{|l|}{ ANC attendance } \\
\hline Yes & $194(90.2)$ & $456(70.8)$ & $3.8(2.4,6.2)$ & $3.9(2.4,6.5)^{* * *}$ \\
\hline No & $21(9.8)$ & $188(29.2)$ & 1 & 1 \\
\hline
\end{tabular}

Notes: ${ }^{*} \mathrm{p}<0.05,{ }^{*} \mathrm{p}<0.01$, and ${ }^{* * *} \mathrm{p}<0.001 .+=$ Government employee, private business and merchant.

compared to their counterparts. This finding is in agreement with other studies conducted in Ethiopia, Ghana, Nigeria, and Nepal. ${ }^{29-35}$ Education improves the mother's information processing skills and cognitive skills. This could again exert mothers to seek better health services, including health facility delivery.

Mothers who have a mobile were two times more likely to deliver in a health facilities as compared to their counterparts. This finding is supported by studies done in Ethiopia and Pakistan. ${ }^{36,37}$ However, few local studies revealed a non-significant relationship between health facility delivery and possession of mobile. ${ }^{38}$ The variability might be attributed to the fact that more than threefourth of the mothers included in this study had no formal education. These mothers might have limited skills to interact through their mobile regarding the benefits of health facility delivery.

Increasing parity was negatively associated with the odds of health facility delivery. A unit increase in the birth order of mothers showed a $15 \%$ decrease in the odds of health facility delivery. This result is supported by other studies done in Ethiopia and abroad. ${ }^{29,39-42}$ Mothers whose age range from 18 to 25 years at first pregnancy were two times more likely to use health facility delivery as compared to those mothers whose age was less than 18 years of age. This finding is not supported by other local studies done in Ethiopia $^{43-45}$ and $\mathrm{Nepal}^{46}$ which revealed that younger 
women tended to deliver at a health facilities compared to older ones. Usually, younger mothers who had no previous experiences in giving birth might have a great fear of complications relating to pregnancy, labor, and childbirth. On the other hand, getting pregnancy before 18 years of age might limit their awareness to utilize health care services including health facility delivery.

This study also found that distance from the health center was a problem for health facility delivery. Mothers living within $1 \mathrm{~km}$ distance from a health center were three times higher odds of health facility delivery as compared to those mothers living beyond $11 \mathrm{~km}$. This finding is consistent with other studies conducted in Ethiopia, Eritrea, Kenya and Nigeria. ${ }^{47-50}$ This may be attributed to the fact that the longer the distance to reach health facility the accessibility to transport and affordability to cover the cost might be in question, which favors home delivery.

\section{Limitation of the Study}

The study identified the determinants of health facility delivery among women who gave birth in the last six months, which might have introduced recall bias. Second, a similar tool was employed for both facility and home-delivered mothers to collect data from the mothers' perspective through interviews by using trained midwives and nurses. Thus, the findings of this study should be interpreted with consideration of these limitations.

\section{Conclusion}

Maternal education, increasing age at first pregnancy, shorter home distance from the nearest health center, and attending ANC visits were the determinants of health facility delivery. Therefore, strengthening education and health-seeking behavior of the mothers using a locally contextualized strategy is essential. Reaching mothers who are still far from health facility needs due attention to benefit them from newborn health services during delivery.

\section{Abbreviations}

ANC, Antenatal care; AOR, Adjusted odds ratio; BCG, Bacillus Calmette-Guérin; CI, Confidence interval; COR, Crude odds ratio; ENBC, Essential newborn care; HSDP, Health sector development program; IRB, Institutional review board; ODK, Open data kit; OPV, Oral polio vaccine; PCA, Principal component analysis; PNC, Postnatal care; SD, Standard deviation; WHO, World health organization.

\section{Data Sharing Statement}

We declare that the dataset supporting the conclusions of this article is available from the corresponding author and will be provided upon a reasonable request.

\section{Ethics Approval and Consent to Participate}

Ethical clearance was obtained from the University of Gondar Institutional Review Board (IRB) (reference No. O/V/P/RCS/05/1818/2018). Permission letter was obtained from all administrative districts and kebeles. Written informed consent was secured from the study participants, study participants under the age of 18 years were approved by the ethics committee to provide informed consent on their own behalf, and that this study was conducted in accordance with the Declaration of Helsinki. Also, they were informed about the potential benefits, confidentiality, and the possibility of withdrawing from the interview even without giving reasons. All interviews were conducted in private settings.

\section{Acknowledgments}

The authors thank all the study participants, interviewers, local administrations, language editor, and WHO for funding this research project.

\section{Author Contributions}

All authors made a significant contribution to the work reported, whether that is in the conception, study design, execution, acquisition of data, analysis and interpretation, or in all these areas; took part in drafting, revising or critically reviewing the article; gave final approval of the version to be published; have agreed on the journal to which the article has been submitted; and agree to be accountable for all aspects of the work.

\section{Funding}

This research project was funded by the World Health Organization (WHO). The funder was following whether the project was executed scientifically and communicated properly. However, WHO has no role in the design, data collection, analysis and interpretation of the data and in writing the manuscript. All the statements and findings are the responsibility of the investigators.

\section{Disclosure}

The authors declare that they have no competing interests. 


\section{References}

1. Central Statistical Agency (CSA) [Ethiopia] and ICF. Ethiopia Demographic and Health Survey 2016. Addis Ababa: Ethiopia, and Rockville, Maryland, USA: CSA and ICF; 2016.

2. Ethiopian Public Health Institute (EPHI) [Ethiopia] and ICF. Ethiopia Mini Demographic and Health Survey 2019: Key Indicators. Rockville: EPHI and ICF; 2019.

3. WHO. Global Health Observatory (GHO) data. Neonatal mortality, world health statistics data visualizations dashboard; 2018. Available from: http://apps.who.int/gho/data/node.sdg.3-2-data? lang=en. Accessed March 8, 2021.

4. Mangham-Jefferies L, Pitt C, Cousens S, Mills A, Schellenberg J. Costeffectiveness of strategies to improve the utilization and provision of maternal and newborn health care in low-income and lower-middleincome countries: a systematic review. BMC Pregnancy Childbirth. 2014;14(1):1-23. doi:10.1186/1471-2393-14-243

5. Kokebie T. Community based essential newborn care practices and associated factors among women in the rural community of Awabel district. Int J Adv Sci Res. 2015;1(01):17-27. doi:10.7439/ijasr.v1i1.1637

6. World Health Organization \& United Nations Children's Fund (UNICEF). Every newborn progress report: Prog Rep MAY 2015 [Internet]; World Health Organization, 2015. Available from: https:// apps.who.int/iris/handle/10665/255559.

7. Temmerman M, Khosia R, Bhutta ZA, Bustreo F. Are we on the threshold of change towards a new global strategy for women's, children's and adolescents' health. BMJ. 2015;351.

8. Federal Ministry of Health (FMOH) [Ethiopia]. Health Sector Transformation Plan, 2015/16 -2019/20. Addis Ababa, Ethiopia: FMOH.

9. Tadesse GD, Gashaw AB, Solomon MA, Zemene TK. Prevalence of common neonatal illness symptoms in Northwest Ethiopia: a repeated measure cross-sectional study. 2020.

10. Ray S, Bhandari P, Prasad JB. Utilization pattern and associated factors of maternal health care services in Haryana, India: a study based on district level household survey data. Int $J$ Reprod Contracept Obstet Gynecol. 2018;7(3):1154-1163. doi:10.18203/ 2320-1770. ijrcog20180910

11. Central Statistical Agency (CSA). Ethiopia Mini Demographic and Health Survey. Addis Ababa, Ethiopia: FMOH; 2014.

12. Degefie T, Amare Y, Mulligan B. Local understandings of care during delivery and postnatal period to inform home based package of newborn care interventions in rural Ethiopia: a qualitative study. BMC Int Health Human Right. 2014;14(7). doi:10.1186/1472-698X14-17

13. Sutan R, Berkat S. Does cultural practice affects neonatal survival case control study among low birth weight babies in Aceh Province, Indonesia. BMC Pregnancy Childbirth. 2014;14:1-13. doi:10.1186/ 1471-2393-14-342

14. Chichiabellu TY, Mekonnen B, Astawesegn FH, Demissie BW, Anjulo AA. Essential newborn care practices and associated factors among home delivered mothers in Damot pulasa Woreda, southern Ethiopia. Reprod Health. 2018;15(1):162. doi:10.1186/s12978-0180609-1

15. Saaka M, Iddrisu M. Patterns and determinants of essential newborn care practices in rural areas of northern Ghana. Int $J$ Popul Res. 2014;4(1):1-10.

16. Tegene T, Andargie G, Nega A, Yimam K. Newborn care practice and associated factors among mothers who gave birth within one year in Mandura District, Northwest Ethiopia. Clin Mother Child Health. 2015;12(1):1-7. doi:10.4172/2090-7214.1000172

17. Elizabeth F, Alison B, Bondan S, Wayan S. Do women increase their use of reproductive health care when it becomes more available? Evidence from Indonesia. Stud Fam Plann. 2009;40:27-38. doi:10.1111/j.1728-4465.2009.00184.x

18. WHO. The Millennium Development Goals Report. 2011:28-35
19. Ahmed A. Maternal Mortality Trend in Ethiopia. Ethiop $J$ Health Dev. 2010;24:115-122.

20. Raleigh V, Hussey D, Seccombe I, Hallt K. Ethnic and social inequalities in women's experience of maternity care in England: results of a national survey. $J$ R Soc Med. 2010;103(5):188-198. doi:10.1258/ jrsm.2010.090460

21. Rana TG, Chataut BD, Shakya G, Nanda G, Pratt A, Sakai S. Strengthening emergency obstetric care in Nepal: the women's right to life and health project (WRLHP). Int J Gynecol Obstetrics. 2007;98(3):271-277. doi:10.1016/j.ijgo.2007.05.017

22. Paxton A, Bailey P, Lobis S. The United Nations process indicators for emergency obstetric care: reflections based on a decade of experience. Int J Gynecol Obstetrics. 2006;95(2):192-208. doi:10.10 16/j.ijgo.2006.08.009

23. Lawn JE, Kinney M, Lee AC, et al. Reducing intrapartum-related deaths and disability: can the health system deliver? Int $J$ Gynecol Obstetrics. 2009;107(Suppl 1):S123-142. doi:10.1016/j.ijgo.2009. 07.021

24. Gedefaw AF, Fentie A, Seblewongiel AK. Facility delivery and postnatal care services use among mothers who attended four or more antenatal care visits in Ethiopia: further analysis of the 2016 demographic and health survey. BMC Pregnancy Childbirth. 2019;19:64. doi:10.1186/s12884-019-2216-8

25. ICF C. Ethiopia Demographic and Health Survey. Addis Ababa, Ethiopia, and Rockville, Maryland, USA: CSA and ICF DF-1.6; 2016.

26. Hagos S, Shaweno D, Assegid M, Mekonnen A, Afework MF, Ahmed S. Utilization of institutional delivery service at Wukro and Butajera districts in the northern and south Central Ethiopia. BMC Pregnancy Childbirth. 2014;14(1):178. doi:10.1186/1471-2393-14178

27. Negero MG, Mitike YB, Worku AG, Abota TL. Skilled delivery service utilization and its association with the establishment of Women's health development Army in Yeky district, south West Ethiopia: a multilevel analysis. BMC Res Notes. 2018;11(1):83. doi:10.1186/s13104-018-3140-0

28. Kruk ME, Rockers PC, Mbaruku G, Paczkowski MM, Galea S. Community and health system factors associated with facility delivery in rural Tanzania: a multilevel analysis. Health Policy (New York). 2010;97(2-3):209-216. doi:10.1016/j.healthpol.2010.05. 002

29. Mezmur M, Navaneetham K, Letamo G, Bariagaber H. Individual, household and contextual factors associated with skilled delivery care in Ethiopia: evidence from Ethiopian demographic and health surveys. PLoS One. 2017;12(9):e0184688. doi:10.1371/journal.pone. 0184688

30. Bhandari TR, Kutty VR, Sarma PS, Dangal G. Safe delivery care practices in western Nepal: does women's autonomy influence the utilization of skilled care at birth? PLoS One. 2017;12(8):e0182485. doi:10.1371/journal.pone.0182485

31. Tekelab T, Yadecha B, Melka AS. Antenatal care and women's decision making power as determinants of institutional delivery in rural area of Western Ethiopia. BMC Res Notes. 2015;8(1):769. doi:10.1186/s13104-015-1708-5

32. Weldemariam S, Kiros A, Welday M. Utilization of institutional delivery service and associated factors among mothers in North West Ethiopian. BMC Res Notes. 2018;11(1):194. doi:10.1186/ s13104-018-3295-8

33. Boah M, Mahama AB, Ayamga EA. They receive antenatal care in health facilities, yet do not deliver there: predictors of health facility delivery by women in rural Ghana. BMC Pregnancy Childbirth. 2018;18(1):125. doi:10.1186/s12884-018-1749-6

34. Tadele N, Lamaro T. Utilization of institutional delivery service and associated factors in bench Maji zone, and Southwest Ethiopia: community based, cross sectional study. BMC Health Serv Res. 2017;17(1):101. doi:10.1186/s12913-017-2057-y 
35. Adewemimo AW, Msuya SE, Olaniyan CT, Adegoke AA. Utilisation of skilled birth attendance in northern Nigeria: a cross-sectional survey. Midwifery. 2014;30(1):e7-e13. doi:10.1016/j.midw.2013.09. 005

36. Feyissa TR, Genemo GA. Determinants of institutional delivery among childbearing age women in Western Ethiopia, 2013: unmatched case control study. PLoS One. 2014;9(5):e97194. doi:10. 1371/journal.pone.0097194

37. Agha S, Carton TW. Determinants of institutional delivery in rural Jhang, Pakistan. Int J Equity Health. 2011;10(1):31. doi:10.1186/ 1475-9276-10-31

38. Birmeta K, Dibaba Y, Woldeyohannes D. Determinants of maternal health care utilization in Holeta town, central Ethiopia. BMC Health Serv Res. 2013;13(1):256. doi:10.1186/1472-6963-13-256

39. Berelie Y, Dawit Y, Leltework Y, Muluneh A. Determinants of institutional delivery service utilization in Ethiopia: a population based cross sectional study. BMC Public Health. 2020;20:1077. doi:10.1186/s12889-020-09125-2

40. Zhang R, Li S, Li C, et al. Socioeconomic inequalities and determinants of maternal health services in Shaanxi Province. Western China. PLoS One. 2018;13(9):e0202129. doi:10.1371/journal.pone.02 02129

41. Ochako R, Fotso J-C, Ikamari L, Khasakhala A. Utilization of maternal health services among young women in Kenya: insights from the Kenya demographic and health survey, 2003. $B M C$ Pregnancy Childbirth. 2011;11(1):1. doi:10.1186/1471-2393-11-1

42. Doctor HV, Nkhana-Salimu S, Abdulsalam-Anibilowo M. Health facility delivery in sub-Saharan Africa: successes, challenges, and implications for the 2030 development agenda. BMC Public Health. 2018;18(1):765. doi:10.1186/s12889-018-5695-z
43. Yoseph M, Solomon MA, Fantahun AM, Mekonnen S, Kedir AG. Institutional delivery services utilization and its determinant factors among women who gave birth in the past 24 months in Southwest Ethiopia. BMC Health Serv Res. 2020;20:265. doi:10.1186/s12913020-05121-9

44. Chernet AG, Dumga KT, Cherie KT. Home delivery practices and associated factors in Ethiopia. J Reprod Infertil. 2019;20(2):102-108.

45. Wolelie A, Aychiluhm M, Awoke W. Institutional delivery service utilization and associated factors in Banja District, Awie zone, Amhara regional sate, Ethiopia. Open J Epidemiol. 2014;4(01):30. doi:10.4236/ojepi.2014.41006

46. Dhakal P, Shrestha M, Baral D, Pathak S. Factors affecting the place of delivery among mothers resid-ing in jhorahat VDC, Morang, Nepal. Int J Commu Based Nurs Midwifery. 2018;6(1):2-11.

47. Fisseha G, Berhane Y, Worku A, Terefe W. Distance from health facility and mothers' perception of quality related to skilled delivery service utilization in northern Ethiopia. Int $J$ Women Health. 2017;9:749. doi:10.2147/IJWH.S140366

48. Kifle MM, Kesete HF, Gaim HT, Angosom GS, Araya MB. Health facility or home delivery? Factors influencing the choice of delivery place among mothers living in rural communities of Eritrea. $J$ Health Popul Nutr. 2018;37(1):22. doi:10.1186/s41043-018-0153-1

49. Ettarh RR, Kimani J. Influence of distance to health facilities on the use of skilled attendants at birth in Kenya. Health Care Women Int. 2016;37(2):237-249. doi:10.1080/07399332.2014.908194

50. Yaya S, Bishwajit G, Uthman OA, Amouzou A. Why some women fail to give birth at health facilities: a comparative study between Ethiopia and Nigeria. PLoS One. 2018;13(5):e0196896. doi:10.1371/ journal.pone.0196896
International Journal of General Medicine

\section{Publish your work in this journal}

The International Journal of General Medicine is an international, peer-reviewed open-access journal that focuses on general and internal medicine, pathogenesis, epidemiology, diagnosis, monitoring and treatment protocols. The journal is characterized by the rapid reporting of reviews, original research and clinical studies

\section{Dovepress}

across all disease areas. The manuscript management system is completely online and includes a very quick and fair peer-review system, which is all easy to use. Visit http://www.dovepress.com/ testimonials.php to read real quotes from published authors. 